\title{
Comparative trial of benzhexol, amantadine, and levodopa in the treatment of Parkinson's disease
}

\author{
J. D. PARKES, R. C. BAXTER, C. D. MARSDEN, AND J. E. REES \\ From The Parkinson's Disease Clinic, The University Department of Neurology, \\ King's College Hospital, and The Maudsley Hospital, London
}

SYNOPSIS Fourteen slightly disabled patients with Parkinsonism were treated separately with benzhexol, amantadine, and levodopa. Benzhexol and amantadine both gave a $15 \%$ reduction in functional disability and levodopa a $36 \%$ reduction. Benzhexol lessened the rigidity and improved the flexion of posture of Parkinson's disease, but had little or no effect on akinesia and tremor. Amantadine and levodopa caused improvement in all these symptoms. The combination of benzhexol and amantadine was as effective after four weeks of treatment as levodopa was after six months.

The exact value of the different drugs used in the treatment of Parkinson's disease is still uncertain, since in most clinical trials drug combinations rather than single drugs have been studied. Anticholinergic drugs are probably the least effective treatment of definite value, but it is doubtful whether they affect akinesia. Rigidity is certainly improved and, in some patients, tremor may be reduced (Duvoisin, 1965, 1967). Amantadine probably relieves all symptoms, but the suggestion that overall it is slightly more effective than anticholinergic drugs (Schwab and England, 1969) has not been proved. Levodopa is the most active drug; most patients are considerably improved and it is effective against all the symptoms of Parkinson's disease. However, apart from the trial of Cotzias and his colleagues which established the role of levodopa (1969), anticholinergic drugs have been given in addition to levodopa in most clinical trials. Roughly twothirds of all patients with Parkinson's disease improve with levodopa and probably a similar number respond to anticholinergic drugs and amantadine. It is still uncertain whether patients who respond to one of these drugs also respond to the others.

We have therefore studied the effects of benzhexol, amantadine, and levodopa given separately to previously untreated patients with
Parkinson's disease or post-encephalitic Parkin $\stackrel{0}{\mathrm{D}}$ sonism.

\section{METHODS}

Seventeen patients, 10 men and seven women, age 47-79 years (mean age 63) were studied. Fifteen hac idiopathic paralysis agitans; two men had postencephalitic Parkinsonism, as shown by oculogyric crises and a disease duration of over 35 years. No patient with paralysis agitans had previously been given treatment for Parkinson's disease. The duration of illness was from six months to 14 years (mean duration $3 \cdot 1$ years) excluding the two patients with post-encephalitic Parkinsonism. The disability of all patients before treatment was slight, and they could perform normal daily activities of eating, washing, etc. All patients were to some extent akinetic, rigid, and with a flexed posture, and all except one were tremulous. No patient had undergone brain surgery. Disability was scored on the scale of Marsden et al. (1973), in which a high score indicates considerable disability.

MEDICATION The effects of four different treatments were studied. Patients were given either benzhexol $2 \mathrm{mg}$ four times daily for four weeks, amantadine $100 \mathrm{mg}$ twice daily for four weeks, or amantadine $\widetilde{\sigma}$ combined with benzhexol for four weeks. This was $N$ followed by a six month period of levodopa treatment in individually determined doses. The final daily levodopa dosage was from $750 \mathrm{mg}$ to $3 \mathrm{~g}$. 422 
Metoclopramide $10 \mathrm{mg}$ three times daily was given during levodopa therapy to minimize nausea, and other medication was stopped during the first month of levodopa treatment.

Benzhexol, amantadine, and combined benzhexolamantadine treatment was given as a randomlyassigned, double-blind, crossover trial. During both four-week periods in which a single active drug was given, a placebo of similar appearance and taste to the alternative active preparation was given. No placebo was required during combined benzhexol and amantadine treatment. Because of its sideeffects and the need to determine individual dosages, levodopa was not given under double-blind or crossover conditions.

The score for disability was assessed before treatment and after four weeks of benzhexol, amantadine, and benzhexol-amantadine combined treatment. A final assessment was made after six months of levodopa treatment. The score for tremor, rigidity, akinesia, and flexion deformity was determined as well as the total disability score. This clinical assessment was done at the same time of day and patients were questioned at each attendance regarding specified side-effects.

During the benzhexol-amantadine treatment one patient developed pneumonia and two patients deteriorated on changing from combined to single treatment. These three patients were not studied further. Of the patients who completed benzhexol and amantadine treatment, two were so slightly disabled that a trial of levodopa was not justified. Twelve patients were started on levodopa of whom three developed side-effects of sufficient severity to prohibit further treatment. Nine patients completed the six month period of levodopa treatment.

\section{RESULTS}

SUBJECTIVE RESPONSES Fourteen patients completed the first 12 week period; 10 described improvement with amantadine, nine with benzhexol, and 10 with combined benzhexol and amantadine treatment. The combination was rated best of the three by eight patients, and improvement with benzhexol and amantadine was established within three days of commencing treatment. Nine patients completed the levodopa period, and this drug was preferred to previous treatments by six of them. The effect of levodopa increased throughout the treatment period of six months.

INDIVIDUAL DRUG EFFECTS Benzhexol and amantadine treatment separately each produced a reduction in mean total disability score of $15 \%$ from pretreatment scores $(\mathrm{P}<0.05$ in each case). The two drugs in combination produced a $40 \%$ reduction in total disability score at the end of a four-week treatment period $(P<0.01)$. Levodopa reduced the total disability score by $36 \%$ after six months in the nine patients given this drug $(\mathrm{P}<0.01)$. The difference between the reduction of score produced by combined benzhexol and amantadine, and levodopa treatment was not statistically significant. In the nine patients who were given levodopa, the mean improvement had been benzhexol $15 \%$, amantadine $17 \%$, and benzhexol-amantadine $42 \%$ (Tables 1 and 2 ).

DRUG EFFECTS ON TREMOR, AKINESIA, RIGIDITY, AND POSTURE The degree of improvement in all these individual symptoms was least with benzhexol and greatest with levodopa with the single exception of rigidity.

Benzhexol treatment gave a very slight improvement of rigidity and the flexion deformity of Parkinsonism. The effect of benzhexol on

TABLE 1

EFFECT OF INDIVIDUAL AND COMBINED DRUG TREATMENT ON TOTAL DISABILITY SCORES AND SUB-SCORES*

\begin{tabular}{|c|c|c|c|c|c|}
\hline & $\begin{array}{c}\text { Total } \\
\text { disability }\end{array}$ & Akinesia & Tremor & Posture & Rigidity \\
\hline $\begin{array}{l}\text { No treatment } \\
\text { Benzhexol } 8 \mathrm{mg} / \text { day } \\
\text { Amantadine } 200 \mathrm{mg} / \text { day } \\
\text { Benzhexol } 8 \mathrm{mg} \text { and amantadine } 200 \mathrm{mg} / \text { day } \\
\text { Levodopa } 750 \mathrm{mg}-3 \mathrm{~g} / \text { day }\end{array}$ & $\begin{array}{l}31 \cdot 4 \pm 3 \cdot 5 \\
26 \cdot 6 \pm 3 \cdot 4^{*} \\
26 \cdot 6 \pm 3 \cdot 5^{*} \\
18 \cdot 8 \pm 2 \cdot 3 \dagger \\
20 \cdot 1 \pm 3 \cdot 7 \dagger\end{array}$ & $\begin{array}{l}6 \cdot 5 \pm 0 \cdot 9 \\
6 \cdot 4 \pm 0 \cdot 9 \\
6 \cdot 2 \pm 0 \cdot 8 \\
5 \cdot 3 \pm 0 \cdot 8 \\
5 \cdot 6 \pm 1 \cdot 6\end{array}$ & $\begin{array}{l}2 \cdot 3 \pm 0 \cdot 5 \\
2 \cdot 2 \pm 0 \cdot 5 \\
1 \cdot 9 \pm 0 \cdot 1 \\
1 \cdot 5 \pm 0 \cdot 1 * \\
1 \cdot 1 \pm 0 \cdot 8\end{array}$ & $\begin{array}{l}5 \cdot 0 \pm 0.8 \\
4 \cdot 6 \pm 0.6 \\
4 \cdot 0 \pm 0.8 \\
2 \cdot 9 \pm 0.5 \dagger \\
2 \cdot 3 \pm 0.6 *\end{array}$ & $\begin{array}{l}5 \cdot 3 \pm 0 \cdot 4 \\
4 \cdot 8 \pm 0 \cdot 5 \\
5 \cdot 0 \pm 0 \cdot 6 \\
2 \cdot 9 \pm 0 \cdot 5 \dagger \\
3 \cdot 0 \pm 0 \cdot 9 \dagger\end{array}$ \\
\hline
\end{tabular}

* The data for benzhexol and amantadine were obtained from 14 patients; for levodopa from nine patients.

Mean value $\pm I S E M$. The significance of the differences between paired no treatment:treatment periods scores assessed by Wilcoxon's rank test. $* \mathrm{P}<0.05$. $† \mathrm{P}<0.01$. 
TABLE 2

PERCENTAGE IMPROVEMENT IN TOTAL DISABILITY SCORES AND SUB-SCORES CAUSED BY DIFFERENT DRUGS, AND COMBINATION OF BENZHEXOL WITH AMANTADINE

\begin{tabular}{|c|c|c|c|c|c|}
\hline & \multicolumn{5}{|c|}{ Percentage improvement } \\
\hline & $\begin{array}{c}\text { Total } \\
\text { disability }\end{array}$ & Akinesia & Tremor & Posture & Rigidity \\
\hline $\begin{array}{l}\text { Benzhexol } 8 \mathrm{mg} / \text { day } \\
\text { Amantadine } 700 \mathrm{mg} / \text { day } \\
\text { Benzhexol } 8 \mathrm{mg} \text { and amantadine } 200 \mathrm{mg} / \text { day } \\
\text { Levodopa } 750 \mathrm{mg}-3 \mathrm{~g} / \text { day }\end{array}$ & $\begin{array}{l}15 \cdot 3 \\
15 \cdot 3 \\
40 \cdot 1 \\
36 \cdot 0\end{array}$ & $\begin{array}{r}1 \cdot 5 \\
4 \cdot 7 \\
18 \cdot 5 \\
13 \cdot 9\end{array}$ & $\begin{array}{r}4 \cdot 4 \\
17 \cdot 4 \\
34 \cdot 8 \\
52 \cdot 2\end{array}$ & $\begin{array}{r}8 \cdot 0 \\
20 \cdot 0 \\
42 \cdot 0 \\
54 \cdot 0\end{array}$ & $\begin{array}{r}9 \cdot 4 \\
5 \cdot 7 \\
45 \cdot 0 \\
43 \cdot 0\end{array}$ \\
\hline
\end{tabular}

rigidity was a little greater than with amantadine, but much less than with levodopa. Eighty per cent of the reduction in the combined scores for tremor, akinesia, rigidity, and posture with benzhexol was due to improved rigidity and posture. Amantadine had a very slight effect on akinesia and caused a moderate improvement in both tremor and posture. Combined benzhexolamantadine treatment improved all symptoms by more than the sum of the improvement caused by each drug separately. The effect was comparable with that caused by levodopa, and the improvement in both posture and rigidity with the combined treatment was particularly marked $(\mathrm{P}<$ $0 \cdot 01$ ).

Tremor, akinesia, posture, and rigidity improved during levodopa treatment, and the disability due to tremor, flexion of posture, and rigidity was approximately halved in each case after six months of levodopa treatment. The effect on akinesia was less, but was still three times greater than with amantadine, and nine times greater than with benzhexol.

Ten of 14 patients improved as shown by reduction in total disability score with amantadine and 10 with benzhexol. Eight patients responded to both drugs and two to neither drug. The reduction in functional disability produced by benzhexol in individual patients and that caused by amantadine did not show a significant correlation ( $r=0 \cdot 18$, Figure). Eight of nine patients responded to levodopa. One patient, who did not respond to amantadine or benzhexol, improved on levodopa. Seven of the other eight patients given levodopa had improved with amantadine and six had improved with benzhexol. The two patients with postencephalitic Parkinsonism both had a greater

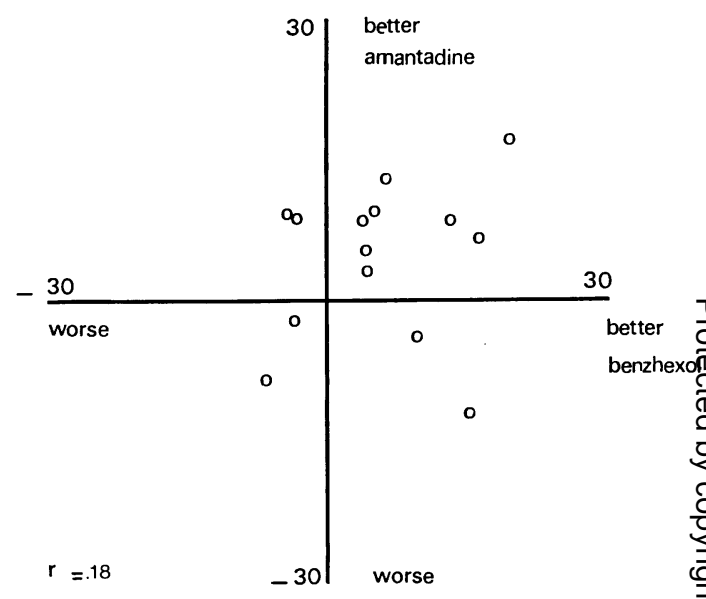

FIGURE Individual patient response to amantadine $200 \mathrm{mg} /$ day and benzhexol $8 \mathrm{mg} /$ day as shown by change in total disability scores.

reduction in total disability on amantadine than on benzhexol. Both were nauseated by levodopa. The correlation between the response to benzhexol and the response to levodopa, as indicated by reduction in total disability, was not statistically significant.

TOXIC EFFECTS Eight of 14 patients with Parkinson's disease complained of a dry mouth before any treatment. This symptom became more severe during benzhexol therapy, but not with amantadine; the combination of benzhexol and amantadine resulted in a dry mouth of moderate severity. Two patients complained of intermittent mental confusion before therapy, but were symptom-free during the months of treatment. Benzhexol and amantadine each pro- 
TABLE 3

SIDE-EFFECTS OF DRUG TREATMENT*

\begin{tabular}{|c|c|c|c|c|c|}
\hline & $\begin{array}{c}\text { No treatment } \\
\text { (14) }\end{array}$ & $\begin{array}{c}\text { Benzhexol } \\
\text { (14) }\end{array}$ & $\begin{array}{c}\text { Amantadine } \\
\text { (14) }\end{array}$ & $\begin{array}{l}\text { Benzhexol and } \\
\text { amantadine } \\
\text { (14) }\end{array}$ & $\begin{array}{c}\text { Levodopa } \\
\text { (9) }\end{array}$ \\
\hline Dry mouth & 8 & 9 & 7 & 11 & 3 \\
\hline Constipation & 5 & 4 & 6 & 3 & 3 \\
\hline Jittery & 0 & 0 & 1 & 0 & 0 \\
\hline Focusing difficulty & 1 & $\mathbf{0}$ & 0 & 0 & 0 \\
\hline Oculogyric crises & 2 & 0 & 1 & 0 & 1 \\
\hline Headache & 5 & 2 & 2 & 1 & 1 \\
\hline Leg swelling & 3 & 0 & 1 & 0 & 0 \\
\hline Nausea & 2 & 1 & 0 & 1 & 6 \\
\hline Vomiting & 1 & 1 & 1 & 1 & 6 \\
\hline Mental confusion & 2 & 2 & 2 & 2 & 0 \\
\hline
\end{tabular}

* The number of patients complaining of each side-effect is shown.

duced mental confusion in patients who had not previously described this. Ankle oedema did not develop during the four-week period of amantadine treatment, but livedo reticularis was seen in two patients. Levodopa caused nausea and/or vomiting in nine of 12 patients. This prevented further treatment in three patients, and in four patients nausea persisted for the six months of treatment, despite the administration of metoclopramide. One patient developed oral-facial dyskinesia during levodopa treatment, but no other involuntary movements were seen.

\section{DISCUSSION}

Benzhexol treatment of Parkinson's disease results in a slight improvement in both rigidity and flexion of posture, and anticholinergic drugs of this type may be useful by themselves or as an adjunct to levodopa in the treatment of patients with considerable postural deformity and rigidity. However, they have little or no effect upon akinesia, either in this or in other studies (Duvoisin, 1965, 1967), while amantadine and levodopa improve all symptoms. The activity of cholinergic and dopaminergic neurones in Parkinson's disease is interdependent but the different range of action and side-effects of benzhexol and levodopa suggest that at least two fundamentally different mechanisms of action are involved. This is also indicated by the poor correlation of individual patient response to benzhexol and levodopa.

Amantadine and levodopa improve all the symptoms of Parkinson's disease. Amantadine augments catecholamine metabolism and causes increased dopamine release during nerve stimulus (Scatton et al., 1970; Strömberg et al., 1970; Farnebo et al., 1971). There is a high correlation between individual patient response to amantadine and response to levodopa which is also in keeping with this effect (Parkes et al., 1970). The improvement with amantadine has been short-lived in some patients (Yahr and Duvoisin, 1972), and this might be due to progressive depletion of dopamine stores. However, several long-term studies of amantadine have not shown loss of effectiveness (Pearce and Rao, 1970; Appleton et al., 1971; Castaigne et al., 1972). This observation is probably due to the natural progression of the disease which is not arrested by amantadine or other treatments.

Levodopa, when given alone, is three times as effective as any other drug and is the treatment of choice for most patients, despite the production of nausea and dose-limiting involuntary movements. Levodopa dosage was restricted in the present patients in view of their minor disability and considerable nausea. The action of levodopa is in keeping with the view that nigrostriatal dopamine deficiency is fundamental to the pathophysiology of Parkinsonism. However, in most patients on levodopa, withdrawal of anticholinergic drugs causes a measurable increase in disability (Hughes et al., 1971).

The initial treatment in any patient with Parkinson's disease should depend upon the degree of disability. Some patients require no treatment. In patients with slight disability a trial of anticholinergic drugs, amantadine, or the 
two combined should be the first treatment. The rapid and considerable improvement with this combination is of value, but in future levodopa combined with a dopa decarboxylase inhibitor may be preferred in patients who require levodopa, as this results in both rapid improvement and minimal nausea (Calne et al., 1971; Marsden et al., 1973). The long-term hazards of levodopa and amantadine treatment are still not known, but as levodopa has now been in regular use for five years, it is unlikely that serious long-term side-effects will emerge. The safety of anticholinergic drugs, however, has been proved during a century of use. Unfortunately, none of the drugs discussed appears to affect the progression of Parkinson's disease.

We are most grateful to Geigy (U.K.) Ltd. for financial assistance towards this study, and to Mrs. P. Barry and Miss M. O'Rourke who gave invaluable nursing and secretarial assistance.

\section{REFERENCES}

Appleton, D. B., Eadie, M. J., and Sutherland, J. M. (1971). The continued use of amantadine hydrochloride in Parkinsonism. Medical Journal of Australia, 2, 707-709.

Calne, D. B., Reid, J. L., Vakil, S. D., Rao, S., Petrie, A., Pallis, C. A., Gawler, J., Thomas, P. K., and Hilson, A. (1971). Idiopathic Parkinsonism treated with an extracerebral decarboxylase inhibitor in combination with levodopa. British Medical Journal, 3, 729-732.

Castaigne, P., Laplane, D., and Dordain, G. (1972). Expérimentation clinique prolongée chez 50 parkinsoniens. Nouvelle Presse Médicale, 1, 533-536.
Cotzias, G. C., Papavasiliou, P. S., and Gellene, R. (1969). Modification of Parkinsonism-chronic treatment with L-dopa. New England Journal of Medicine, 280, 337-345.

Duvoisin, R. C. (1965). A review of drug therapy in parkinsonism. Bulletin of the New York Academy of Medicine, 41, 898-910.

Duvoisin, R. C. (1967). Cholinergic-anticholinergic antagonism in parkinsonism. Archives of Neurology, 17, 124-136.

Farnebo, L., Fuxe, K., Goldstein, M., Hamberger, B., and Ungerstedt, U. (1971). Dopamine and noradrenaline releasing action of amantadine in the central and peripheral nervous system: a possible mode of action in Parkinson's disease. European Journal of Pharmacology, 16, 27-38.

Hughes, R. C., Polgar, J. G., Weightman, D., and Walton, J. N. (1971). Levodopa in Parkinsonism: the effects of withdrawal of anticholinergic drugs. British Medical Journal, 2, 487-491.

Marsden, C. D., Barry, P. E., Parkes, J. D., and Zilkha, K. J. (1973). Treatment of Parkinson's disease with levodopa combined with L-alpha-methyldopahydrazine, an inhibitor of extracerebral DOPA decarboxylase. Journal of Neurology, Neurosurgery, and Psychiatry, 36, 10-14.

Parkes, J. D., Zilkha, K. J., Knill-Jones, R. P., Clements, P. J., and Baxter, R. (1971). L-dopa and amantadine hydrochloride in Parkinson's disease. International Journal of Clinical Pharmacology, Therapy, and Toxicology, 4, 356-360.

Pearce, J., and Rao, N. S. (1970). Amantadine in parkinsonism. Lancet, 2, 1091-1092.

Scatton, B., Cheramy, A., Besson, M. J., and Glowinski, J6 (1970). Increased synthesis and release of dopamine in thळ striatum of the rat after amantadine treatment. Europea Journal of Pharmacology, 13, 131-133.

Schwab, R. S., and England, A. C., Jr. (1969). Amantadine HCL (Symmetrel) and its relation to levo-dopa in the treatment of Parkinson's disease. Transactions of the American Neurological Association, 94, 85-90.

Strömberg, U., Svensson, T. H., and Waldeck, B. (1970). On the mode of action of amantadine. Journal of Pharmac
and Pharmacology, 22, 959-962.

Yahr, M. D., and Duvoisin, R. C. (1972). Drug therapy of Parkinsonism. New England Journal of Medicine, 287, 2024. 